\title{
A New Method for the Quantification of Rhizoctonia solani and R. oryzae from Soil
}

\author{
T. C. Paulitz and K. L. Schroeder, United States Department of Agriculture, Agricultural Research Service, Root \\ Disease and Biological Control Unit, Pullman, WA 99164-6430
}

\begin{abstract}
Paulitz, T. C., and Schroeder, K. L. 2005. A new method for the quantification of Rhizoctonia solani and $R$. oryzae from soil. Plant Dis. 89:767-772.

Rhizoctonia solani anastomosis group (AG) 8 and $R$. oryzae are important root pathogens on wheat and barley in the dryland production areas of the inland Pacific Northwest. $R$. solani AG-8 is difficult to isolate from root systems and quantify in soil because of slow growth and low population densities. However, both pathogens form extensive hyphal networks in the soil and can grow a considerable distance from a food base. A quantitative assay of active hyphae was developed, using wooden toothpicks as baits inserted into sample soils. After 2 days in soil, toothpicks were placed on a selective medium, and the numbers of colonies that grew after $24 \mathrm{~h}$ were counted under a dissecting microscope. $R$. solani and $R$. oryzae could be distinguished from other fungi based on hyphal morphology. This method was tested in natural soils amended with known inoculum densities of $R$. solani AG-8 and $R$. oryzae. Regressions were used to compare the inoculum density or toothpick colonization curves to a predicted curve based on the volume of the toothpicks. The slopes and $y$ intercept of log-log transformed regressions did not differ from the predicted curves in most cases. This technique was used to assess the hyphal activity of $R$. solani AG- 8 and $R$. oryzae from soil cores taken from various positions in and around Rhizoctonia bare patches at two locations. Activity of $R$. solani was highest in the center and inside edge of the patch, but there was no effect of patch position on $R$. oryzae. This simple and inexpensive technique can be used for detection and diagnosis in grower fields and to study the ecology and epidemiology of Rhizoctonia spp.
\end{abstract}

Rhizoctonia solani and $R$. oryzae are important root pathogens of wheat (Triticum aestivum) and barley (Hordeum vulgare) in the dryland production areas of the inland Pacific Northwest. $R$. solani anastomosis group (AG) 8 causes root rot and bare patch and was first discovered in this area in the mid 1980s (43). This disease is more severe in no-till or direct seed systems, which are used to reduce soil erosion and energy inputs $(18,31,34,35$, 38,43). Recently, another species of Rhizoctonia, $R$. oryzae, has been found to be widely distributed, with isolates highly virulent to wheat, barley, and pea (Pisum sativum) (30-32). There is no commercially available genetic resistance $(39,40)$ or chemical control for these diseases; therefore, management relies on cultural practices, primarily management of grassy weeds and volunteers to prevent green bridging of the inoculum into the new crop (31).

One of the problems in working with $R$. solani and $R$. oryzae has been isolating these pathogens from roots or soil, espe-

Corresponding author: T. C. Paulitz

E-mail: paulitz@wsu.edu

Accepted for publication 23 March 2005.

DOI: 10.1094/PD-89-0767

This article is in the public domain and not copyrightable. It may be freely reprinted with customary crediting of the source. The American Phytopathological Society, 2005 cially $R$. solani AG-8, which is slow growing (23). A semiselective medium (water agar amended with benomyl and chloramphenicol) has been used for isolation, but $R$. solani is rarely recovered even from symptomatic roots (T. C. Paulitz and M. Mazzola, unpublished). R. oryzae is faster growing and more easily isolated from roots. Incidence of root colonization and incidence of seminal and crown roots showing symptoms were used to quantify the spatial distribution of $R$. oryzae on a 36-ha farm (33); however, isolation frequency can vary with the age of the roots.

Quantification of Rhizoctonia spp. from soil is difficult. Because of the low inoculum density in soil, dilution plating cannot be used. Various methods have been used to directly isolate from concentrated organic fractions of the soil, including dry sieving (27), wet sieving (44), and elutriation (4), followed by plating of the fractions. Direct plating of soil pellets, cork borer samples, or clumps of soil also have been used to quantify Rhizoctonia populations $(12,13)$.

Baiting methods often have been used to isolate Rhizoctonia spp. from soils. These baits include stems and seed of various plants, including cotton (Gossypium hirsutum), sugar beet (Beta vulgaris), wheat, lima bean (Phaseolus lunatus), and buckwheat (Fagopyrum sagittatum) $(29,41)$. Bait roots (15) and whole plants (10) also have been used to observe pathogen activity in the soil and the spatial distribution of the pathogen, but few of these studies have used baiting as a quantitative method.

Immunological techniques, based on monoclonal antibodies, have been employed to detect and quantify $R$. solani AG-4 (42) and AG-8 (21). However, for practical purposes, this technique is unavailable because there is no commercial kit on the market for Rhizoctonia spp. Polymerase chain reaction (PCR) has been used to detect various AGs and species, but quantitative PCR has been developed only for $R$. solani AG-3 and $R$. cerealis $(16,24)$. One drawback to these methods is the specificity for certain AGs, and most have been applied only to pure cultures, plant samples, or soil extracts.

A reliable and efficient method is needed to isolate and quantify Rhizoctonia spp. from field soils in eastern Washington. A modification of the toothpick baiting method of Kumar et al. (14), who used it to measure the linear spread of $R$ solani AG-11 and AG-8 in sand in greenhouse experiments, was developed to isolate and collect $R$. oryzae and $R$. solani from grower fields in 2002 and 2003. The objective of this work was to standardize the method by developing standard curves from known amounts of inoculum added to natural soils, and to compare these curves with predicted values based on the volume of soil occupied by toothpick bait. This method then was used to quantify the hyphal activity of $R$. solani AG-8 and $R$. oryzae at various positions within and around Rhizoctonia bare patches of cereals at two locations in eastern Washington.

\section{MATERIALS AND METHODS}

Soils. Soil samples were collected from the top $15 \mathrm{~cm}$ (6 in.) of the soil profile at the Washington State University (WSU) Cunningham Agronomy Farm and the Agricultural Research Service Palouse Conservation Field Station, (both near Pullman, WA; Thatuna fine silty loam soils), and from the WSU Dryland Research Station at Lind, WA (Ritzville course silty loam). All soils were air dried, sieved through a 2-mm-opening sieve, and stored at room temperature until use.

Inoculum. Inocula of $R$. solani AG-8 isolate $\mathrm{C} 1$ (22) and $R$. oryzae isolate 801387 (30) were produced on autoclaved oat (Avena sativa) seed. Oat seed $(250 \mathrm{ml})$ and $250 \mathrm{ml}$ of water were added to 1-liter Erlenmeyer flasks and autoclaved twice for $90 \mathrm{~min}$ on two consecutive days. Flasks were seeded with 10 plugs from 1-weekold Rhizoctonia spp. potato dextrose agar 
cultures. Flasks were shaken once per week and incubated at room temperature for 4 weeks. Colonized oat seed were spread out on kraft paper, dried for 2 days under a laminar flow hood, and ground with a coffee grinder. Inoculum was passed through a sieve with 1-mm openings and collected on a sieve with $250-\mu \mathrm{m}$ openings. Particles larger than $1 \mathrm{~mm}$ or smaller than $250 \mu \mathrm{m}$ were not used as inoculum. Inoculum was stored at $4^{\circ} \mathrm{C}$ until use. Inoculum density was quantified by dilution plating on a Rhizoctonia selective medium (water agar amended with benomyl at $1 \mu \mathrm{g} / \mathrm{ml}$ and chloramphenicol at $100 \mu \mathrm{g} / \mathrm{ml}$ ). Colonies were counted after 24 or $48 \mathrm{~h}$.

Inoculum density-toothpick colonization experiments. Inoculum was mixed into $1-\mathrm{kg}$ portions of dry soil at concentrations of $0,0.5,1,2,5,10$, and $20 \mathrm{CFU} / \mathrm{g}$. Soil from each dilution was mixed in a plastic bag and dispensed into five 5-by-5by- $6.5 \mathrm{~cm}$ plastic pots (1.0 final bulk density of the soil). Water was added to the pots at $15 \% \mathrm{wt} / \mathrm{wt}$ and pots were incubated in a temperature-controlled growth room at a constant $16^{\circ} \mathrm{C}$. At 1,2 , or 3 days after wetting, depending on the experiment, five flat wooden white birch toothpicks $(6 \mathrm{~cm}$ long by $1 \mathrm{~mm}$ deep by 1-2 mm wide; Diamond Brands, Minneapolis, MN) were inserted into the soil to a depth of $5 \mathrm{~cm}$, evenly spaced in the pot. After $48 \mathrm{~h}$, toothpicks were removed and placed on plates of Rhizoctonia selective medium (five toothpicks per plate). After $24 \mathrm{~h}$, plates were examined under a dissecting scope (Olympus SZ 10-40 X) with transmitted light and using a 5-mm grid underneath the plate (Fig. 1A). Each toothpick was scanned, and the numbers of squares adjacent to the toothpick containing a colony of $R$. solani, $R$. oryzae, or both were counted (Fig. 1B). Experiments were conducted twice in each soil.

Assessment of hyphal density at different positions in and around Rhizoctonia bare patches. Transects were sampled across eight separate Rhizoctonia bare patches from each of two locations near Ritzville (Ritzville silt loam) and Starbuck,
WA (Walla Walla silt loam) in July 2002, for a total of 16 patches. The sites were planted with spring wheat (cv. Alpowa) at Ritzville and spring barley (cv. Baronesse) at Starbuck. Cores $(15$ by $25 \mathrm{~cm}$ ) were cut from PVC sewer pipe, and the bottom end was tapered with a grinder to facilitate penetrating the soil. Cores were pounded with a weighted slide device and extracted with a lever arm. The weighted slide device consisted of a metal plate that fit on top of the core, with a $90-\mathrm{cm}(3-\mathrm{ft})$ metal pole attached to the plate. A largerdiameter metal pole with a truck brake drum attached to the bottom slid up and down over the smaller pole, pounding the metal plate and core into the soil. At each patch, a core was removed from the center, $1 \mathrm{~m}$ inside the edge of the patch (inside edge), $1 \mathrm{~m}$ outside the edge of the patch (outside edge), and from adjacent healthy plants. In all, 64 cores were collected. Fiberglass screen was secured to the bottom of the cores to keep them intact. Cores were wetted on 4 November 2002 and planted with 10 barley seed (cv. Baronesse). The cores were maintained in a temperature-controlled greenhouse bay, at a constant temperature $\left(16 \pm 1^{\circ} \mathrm{C}\right)$, with supplemental lighting using sodium vapor lights for $12 \mathrm{~h} /$ day, and watered every 2 to 3 days, as needed. Two weeks after planting, 10 toothpicks were inserted into each core, removed 2 days later, and plated on the Rhizoctonia selective medium previously described. One week later, shoots of the barley plants were cut off, without disturbing the soil, and new seed were planted into the cores. Two weeks after planting, the quantification of hyphal activity was repeated again as described above.

Data analyses. For the inoculum density-toothpick colonization experiments, the total number of colonies on each plate (from five toothpicks) was calculated, with five replicate pots per inoculum dilution. The added inoculum density $(i)$ (CFU/g of soil) value and the number of colonies per five toothpicks were log-transformed to $i=$ $\log _{10}(x+1)$. Linear regressions were per-

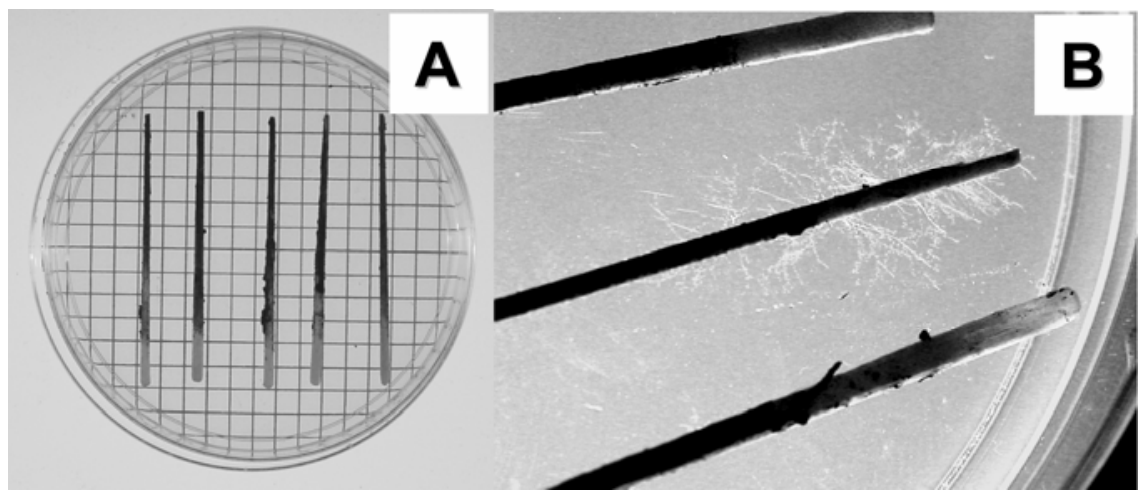

Fig. 1. Toothpick assay. A, Five toothpicks were removed from soil and placed on a plate of Rhizoctonia selective medium, with 5-mm counting grid underneath. B, Colony of Rhizoctonia solani growing out of toothpick after $24 \mathrm{~h}$. formed on the log-transformed data, with added inoculum density as the independent variable and number of colonies per five toothpicks as the dependent variable, using Sigma Plot 2000 (version 6.0; SPSS, Inc. Chicago). A predicted curve was constructed, based on the volume of one toothpick (estimated at $0.075 \mathrm{~cm}^{3}$ ) or a total volume of $0.375 \mathrm{~cm}^{3}$ for five toothpicks. This assumed that all propagules displaced by the volume of the toothpick were in contact with the surface of the toothpick, germinated to produce hyphae, and resulted in a colony. For example, 10 $\mathrm{CFU} / \mathrm{g}$ should result in 3.75 colonies out of five toothpicks. For soils with a background level of $R$. solani or $R$. oryzae, the number of colonies from the noninoculated soil was added to the predicted values at each inoculum density, before transformation and regression. The slope and $y$ intercept coefficients of the actual regressions were compared with the predicted regressions using 95\% confidence limits derived from the standard error values of the actual regressions. In the graphs, the data were expressed on a semilog basis (number of colonies on five toothpicks versus log inoculum density). All inoculum density or toothpick colonization trials were repeated once for each soil. Data for the bare patch experiment were logtransformed $\left(\log _{10}\right.$ [propagules/g +1$\left.]\right)$, analyzed with analysis of variance, and the means of patch location were compared using a least significant difference test at $P$ $=0.05$ (Statistix version 7, Analytical Software, Inc., Tallahassee, FL). If the variances were unequal or data were not normally distributed, a nonparametric Kruskal-Wallis one-way analysis of variance was used.

\section{RESULTS}

Morphology of $\boldsymbol{R}$. solani and $\boldsymbol{R}$. oryzae growing from toothpicks. $R$. solani and $R$. oryzae produced a distinctive colony morphology which easily could be seen and counted. $R$. solani produced wide hyphae, right-angle branching with constriction at the point of branching, and a dolipore septum in the branch near the point of constriction (Fig. 2A). Secondary hyphae often were curled and grew randomly in different directions instead of growing in one direction (Fig. 2B). This resulted in a random orientation of hyphae under the dissecting scope (Fig. 2C). Hyphae of $R$. solani also appeared shiny golden, due to refraction from lipid bodies or vacuoles in the young hyphae (Fig. 2B). In contrast, $R$. oryzae was faster growing and produced a characteristic pattern of hyphae, with secondary branching at 30 to 50 degrees from the main hypha (Fig. 2D and E).

Inoculum density-toothpick colonization curves. Within the range tested of 0.5 to $20 \mathrm{CFU} / \mathrm{g}$, the relationship between inoculum density added to the soil and the number of colonies from the toothpicks 
was described by a linear regression. This relationship between the number of colonies and the log of inoculum density was determined for $R$. oryzae (Fig. 3) and $R$. solani (Fig. 4). Both the Cunningham and Palouse Conservation soils (Fig. 3A and 3B) contained background levels of $R$. oryzae, from 0.4 to 1.2 colonies/five toothpicks. The soil from the WSU Dryland Research Station also contained background levels of $R$. solani (five colonies/five toothpicks) (Fig. 4C), but not $R$. oryzae. Linear models gave significant fits to all data sets, with $r^{2}$ values ranging from 0.30 to 0.75 (Table 1). The slopes and $y$-intercept values of the actual regressions did not differ significantly from the predicted regressions, except for the $y$-intercept of $R$. oryzae in the Palouse Conservation soil. Results of the first trials are presented, but the trends were the same in both trials (i.e., toothpick colonization was proportional to the added inoculum density).

Each toothpick occupied a volume of $0.075 \mathrm{~cm}^{3}$, or a total volume of $0.375 \mathrm{~cm}^{3}$ for five toothpicks. Therefore, one colony per five toothpicks $=1$ propagule $/ 0.375$ $\mathrm{cm}^{3}$ of soil. The bulk density of the soil was 1 ; therefore, 1 propagule $/ 0.375 \mathrm{~cm}^{3}$ of soil $=1$ propagule $/ 0.375 \mathrm{~g}$ of soil $=2.67$ propagules/g soil. Therefore, the predicted relationship between propagules per gram of soil and number of colonies on the toothpicks is density of hyphae (propagules $/ g$ soil $)=2.67 \times$ total number of colonies on five toothpicks.

Assessment of hyphal density at different positions in and around Rhizoctonia bare patches. At the Ritzville site, the highest levels of toothpick colonization with $R$. solani were found in the center and inside edge of the patches, which differed significantly from the outside and outside edge, respectively (Fig. 5). Based on the predicted regressions, there were 87 and $57 \mathrm{CFU} / \mathrm{g}$ of soil at the center and inside edge, respectively. Outside of the patch, within the area of healthy plants, the average hyphal density of $R$. solani was 14 $\mathrm{CFU} / \mathrm{g}$. There was no significant difference among patch positions for $R$. oryzae, which ranged from 2 to $13 \mathrm{CFU} / \mathrm{g}$. Of the eight patches sampled, two did not contain any active $R$. solani at the center of the patch. At the Starbuck site, there was much higher variation among the patch transects, and four patches did not contain any detectable $R$. solani at the centers. Colony counts ranged from 0 to 28 in the center of the patches and from 0 to 14 at the inside edge. However there was still a significant effect of patch position, with higher colony counts from the center and inside edge of the patches (Fig. 6). R. oryzae was found in much lower densities, with no significant effect of patch position.

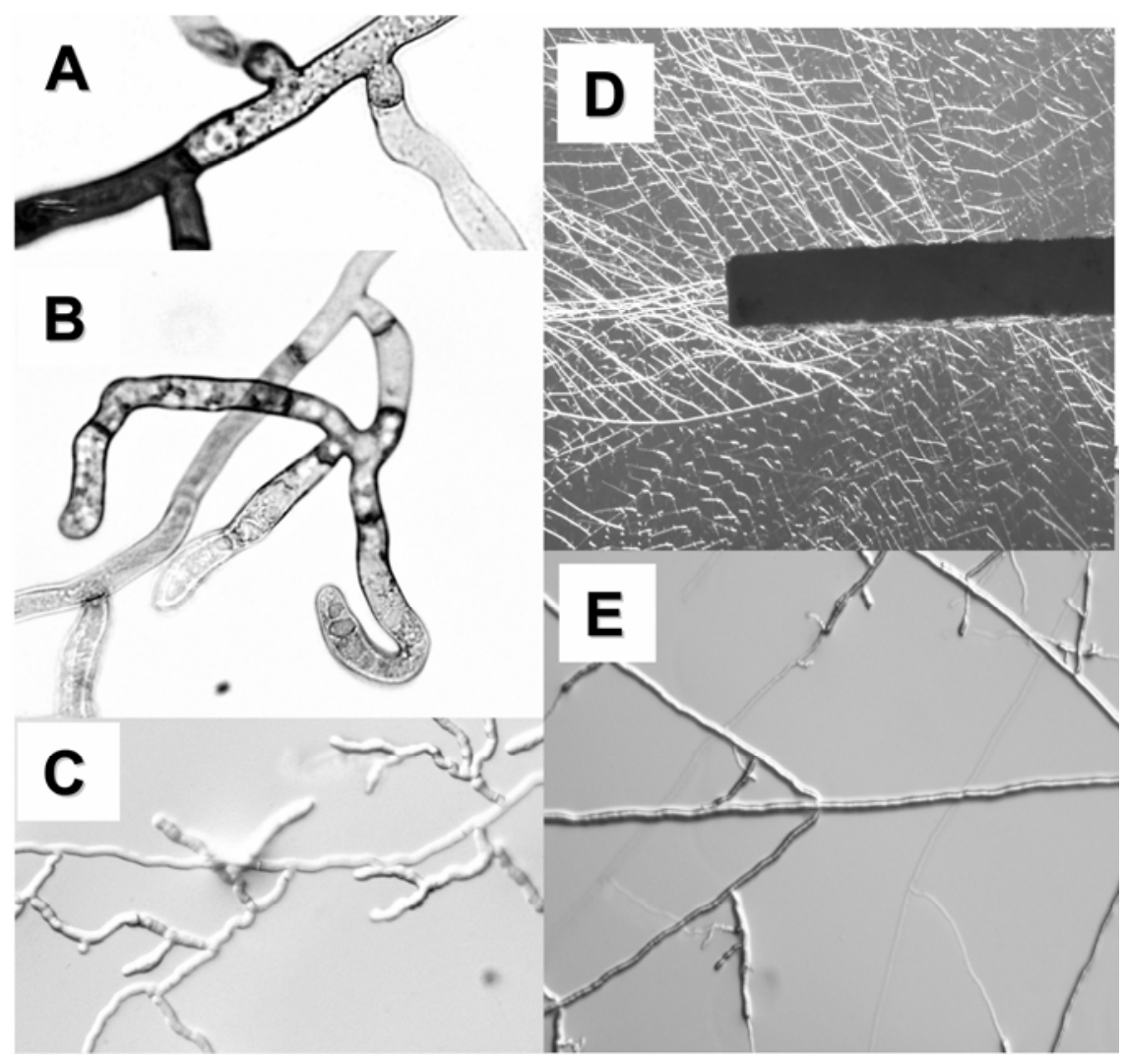

Fig. 2. Hyphae of Rhizoctonia oryzae and $R$. solani growing from toothpicks. A, B, and C, R. solani. A, Typical right-angle branching of main hyphae of $R$. solani, with constriction at the point of branching. B, Curling growth of young secondary hyphae. Young hyphae are highly vacuolated, and appear shiny golden under dissecting scope. $\mathbf{C}$, Growth of hyphae of $R$. solani in random directions. $\mathbf{D}$ and $\mathbf{E}, R$. oryzae showing unidirectional growth of main hyphae and 30 to $50^{\circ}$ branching of secondary hyphae.

\section{DISCUSSION}

In this study, a quantitative soil assay was developed for $R$. solani and $R$. oryzae using wooden toothpicks as bait. This method was used successfully to assess the activity of $R$. solani inside and outside of bare patches in wheat fields. This method also has been used to compare the activity of $R$. solani over time in direct-seed plots versus conventionally tilled plots in replicated field trials (36). R. solani, unlike
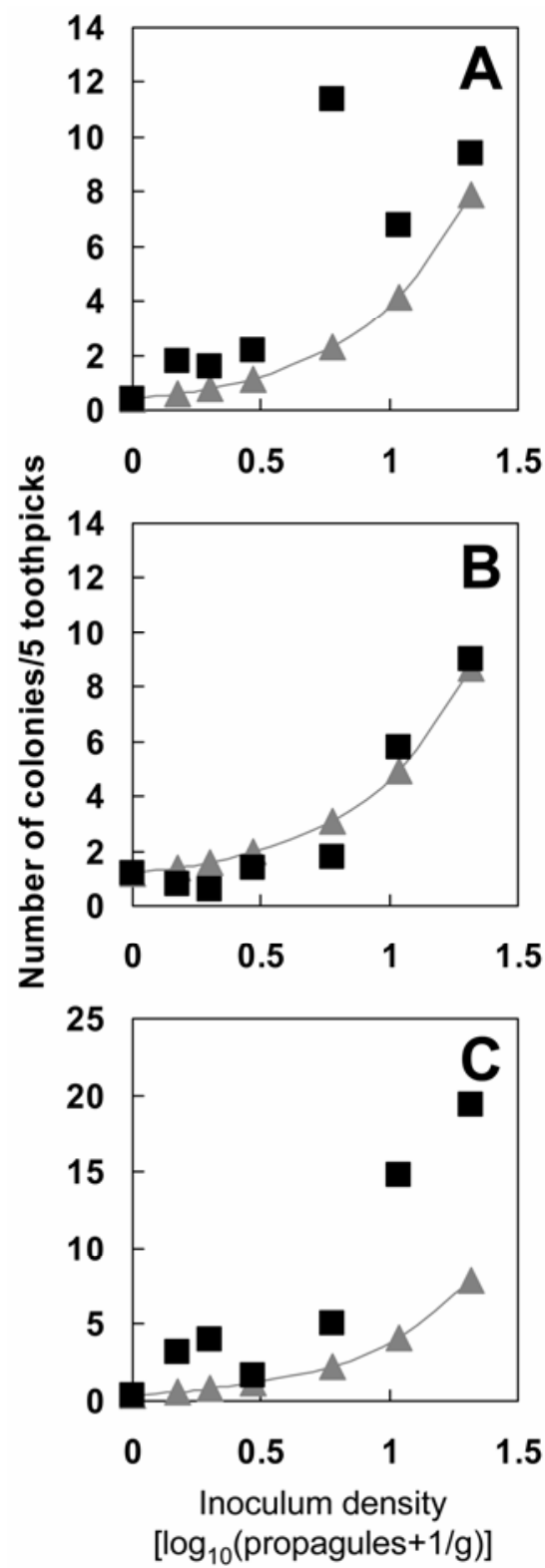

Fig. 3. Inoculum density-toothpick colonization curves of Rhizoctonia oryzae in three different soils. A, Cunningham Farm (Thatuna fine silty loam). B, Palouse Conservation Field Station (Thatuna fine silty loam). C, Washington State University Dryland Research Station (Ritzville course silty loam). Inoculum was added to dry soil at inoculum densities of $0,0.5,1,2,5,10$, and $20 \mathrm{CFU} / \mathrm{g}$. There were five replicate pots per dilution. Pots were wetted and toothpicks were inserted $24 \mathrm{~h}$ later in the Cunningham and Lind soils, and after $48 \mathrm{~h}$ in the Palouse soil. Squares represent actual data; triangles and solid line represent predicted values. 
many soilborne pathogens, can grow quickly and extensively from a food base into natural soil (8) and it has the ability to transfer cytoplasmic contents and nutrients throughout the hyphal network (6). This ability for long-distance growth has been demonstrated by many studies showing infection of plants at a distance from the inoculum source $(2,9)$. Hyphae grow through pores and along soil surfaces, and this distribution was altered by the bulk
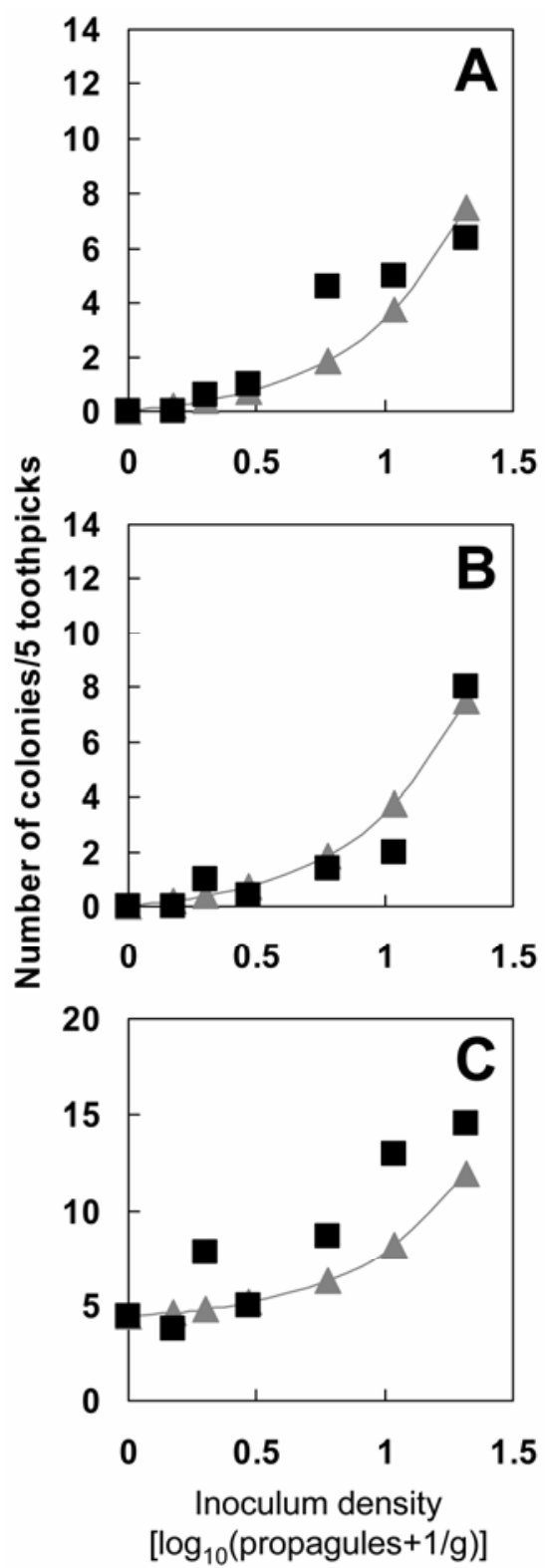

Fig. 4. Inoculum density-toothpick colonization curves of Rhizoctonia solani in three different soils. A, Cunningham Farm (Thatuna fine silty loam). B, Palouse Conservation Field Station (Thatuna fine silty loam). C, Washington State University Dryland Research Station (Ritzville course silty loam). Inoculum was added to dry soil at inoculum densities of $0,0.5,1,2,5,10$, and $20 \mathrm{CFU} / \mathrm{g}$. There were five replicate pots per dilution. Pots were wetted and toothpicks were inserted $24 \mathrm{~h}$ later in the Cunningham and Lind soils, and after $72 \mathrm{~h}$ in the Palouse soil. Squares represent actual data, triangles and solid line represent predicted values. density of the soil (11). Interestingly, $R$. solani seems to grow faster along surfaces than through a porous substrate like sand (26). Thus, it is not unexpected that $R$. solani can produce a hyphal network that encounters a toothpick within this threshold distance, and can thigmotropically attach and grow along the surface of the wood. The interaction between Rhizoctonia spp. and the toothpick probably is thigmotrophic rather than chemotrophic, similar to the role of surface topography of cotton roots in the differentiation of infection cushions of $R$. solani (1). It is unlikely that $R$. solani is chemotactically attracted to toothpicks. However, $R$. solani can decompose cellulose $(5,7,28)$, which may be present in the toothpicks, and also can colonize fresh bark (3). Hyphae on the surface of the toothpick also may use transported nutrients from an adjacent food base.

Because our toothpick method only detects an active hyphal network, it cannot be used to quantify total inoculum in the soil. For example, sclerotia of $R$. oryzae would not be detected unless they had germinated. These sclerotia can germinate in the absence of the host, and an increase in toothpick colonization of $R$. oryzae follows wetting of a dry field soil. Two weeks after inoculum of $R$. oryzae is added to a natural soil, the number of colonies on toothpicks dramatically declines, presumably because of the conversion of hyphae to sclerotia (36). This method would provide an accurate estimate of inoculum potential of a soil at a given time, because hyphae initiate the infection process.

A period of time is required after wetting a dry soil before adding the tooth- picks. Based on preliminary time course experiments, the soil must be wetted and incubated for 1 to 3 days before insertion of the toothpicks. This allowed enough time for the Rhizoctonia spp. to resume growth and produce hyphae to contact the toothpicks. During this period, the slope of the inoculum density or toothpick colonization curve did not differ significantly from the predicted curve. If the soil was incubated for a longer period, the slope values increased significantly, especially for $R$. oryzae (unpublished data). The fact that the slopes of the predicted and actual curves agree indicates that, during this early period, each piece of inoculum is producing one colony on the toothpick. Sneh et al. (41) found that the highest level of colonization of numerous baits by Rhizoctonia spp. occurred after 2 to 4 days of incubation. Their study also found a high positive correlation between added inoculum density of $R$. solani and percentage of stem pieces that were colonized.

The toothpick method appears to be reproducible across different soils; however, ideally, a calibration curve should be developed for each soil and incubation temperature. Higher temperatures may reduce the time that the soil should be incubated before inserting toothpicks. We used $16^{\circ} \mathrm{C}$, because both $R$. solani AG- 8 and $R$. oryzae are pathogenic to cereals at 10,12 , and $20^{\circ} \mathrm{C}(22,25)$, and this temperature would be typical of soil temperatures late in fall or early in the spring when most of the damage probably occurs. This method is low cost and easy to perform. It also can be used in soils without roots, so that studies can be conducted on soils sampled

Table 1. Regression models of inoculum density-toothpick colonization curves and comparison with predicted curve for soils collected from three sites in eastern Washington

\begin{tabular}{|c|c|c|c|c|}
\hline Location, fungus $^{a}$ & Regression & Slope $^{b}$ & $Y_{\mathbf{0}}^{\mathrm{b}}$ & $R^{2}$ \\
\hline \multicolumn{5}{|l|}{ Cunningham } \\
\hline \multirow[t]{3}{*}{ Rhizoctonia solani } & Actual & $0.74 \pm 0.07$ & $-0.05 \pm 0.05$ & 0.75 \\
\hline & Predicted & $0.71 \pm 0.03$ & $-0.05 \pm 0.02$ & 0.99 \\
\hline & Actual versus predicted ${ }^{c}$ & NS & NS & \\
\hline \multirow[t]{3}{*}{ R. oryzae } & Actual & $0.73 \pm 0.10$ & $0.17 \pm 0.07$ & 0.62 \\
\hline & Predicted & $0.61 \pm 0.04$ & $0.09 \pm 0.03$ & 0.98 \\
\hline & Actual versus predicted & NS & NS & $\ldots$ \\
\hline \multicolumn{5}{|l|}{ Palouse } \\
\hline \multirow[t]{3}{*}{ R. solani } & Actual & $0.60 \pm 0.10$ & $-0.08 \pm 0.07$ & 0.52 \\
\hline & Predicted & $0.71 \pm 0.03$ & $-0.05 \pm 0.02$ & 0.99 \\
\hline & Actual versus predicted & NS & NS & \\
\hline \multirow[t]{3}{*}{ R. oryzae } & Actual & $0.55 \pm 0.12$ & $0.08 \pm 0.09$ & 0.40 \\
\hline & Predicted & $0.49 \pm 0.04$ & $0.28 \pm 0.03$ & 0.96 \\
\hline & Actual versus predicted & NS & $\mathrm{S}$ & $\ldots$ \\
\hline \multicolumn{5}{|c|}{ 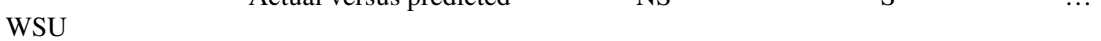 } \\
\hline \multirow[t]{3}{*}{ R. solani } & Actual & $0.41 \pm 0.11$ & $0.62 \pm 0.08$ & 0.30 \\
\hline & Predicted & $0.21 \pm 0.03$ & $0.71 \pm 0.01$ & 0.94 \\
\hline & Actual versus predicted & NS & NS & $\ldots$ \\
\hline \multirow[t]{3}{*}{ R. oryzae } & Actual & $0.79 \pm 0.11$ & $0.22 \pm 0.08$ & 0.60 \\
\hline & Predicted & $0.61 \pm 0.04$ & $0.08 \pm 0.03$ & 0.98 \\
\hline & Actual versus predicted & NS & NS & $\ldots$ \\
\hline
\end{tabular}

a Soil type at the Cunningham Farm (Cunningham) and Palouse Conservation Field Station (Palouse) was a Thatuna fine silty loam; at Washington State University Dryland Research Station (WSU), it was a Ritzville course silty loam.

${ }^{\mathrm{b}}$ Data \pm standard error; NS = not significant and $\mathrm{S}=$ significant.

${ }^{\mathrm{c}}$ Coefficients compared with 95\% confidence intervals calculated from standard error and $t=2.03$, with 34 degrees of freedom. 
throughout the season. Unlike PCR-based tests, it can quantify numerous AGs of $R$. solani and $R$. oryzae with the same test. However, AGs cannot be distinguished based on the morphology of the hyphae. One other advantage is the ability to monitor Rhizoctonia spp. over time in a nondestructive fashion, without disturbing the soil. Soil disturbance has an adverse effect on patch development and disease caused by $R$. solani AG-8, hence the need to work with intact soil cores $(17,18)$. Our method also works with samples dug from a field and placed into small pots. Presumably, hyphae can survive this disturbance, although disease may not be manifested in disturbed soil (17).

Based on the use of five toothpicks, the theoretical lower threshold of detection would be $2.7 \mathrm{CFU} / \mathrm{g}$ and the upper level would be $133 \mathrm{CFU} / \mathrm{g}$ (based upon 50 possible hits on five toothpicks). The threshold of detection could be lowered by sampling with more toothpicks. $R$. solani is usually present at low population densities. Using a wet screening technique, soils from 26 fields in California contained between 2 and 15 propagules/100 g (44). Inoculum density or disease severity studies have been performed with $R$. solani AG- 8 and $R$. oryzae added to natural soils, and have indicated that significant stunting of barley occurred at 2.5 to 8 propagules/g (37).

Using this technique to study bare patches, we showed that the highest level of $R$. solani AG- 8 occurs in the center or inside edge of the patch. In Australia, the frequency of isolation of $R$. solani from roots was much higher within the patch $(19,20)$, based on isolations from plants growing in soil cores from transects within and between patches. Our toothpick method also detected $R$. solani in soil from the healthy areas of wheat or barley, outside of the patches. MacNish et al. (19) detected $R$. solani AG-8 45 to $75 \mathrm{~cm}$ outside of the edge of patches in the field. In another study (20), the pathogen was rarely detected further than $1 \mathrm{~m}$ away from the edge of the patch. In our study, we found that $R$. solani was not detected in two of eight and four of eight cores taken from the centers of patches in Ritzville and Starbuck, respectively. However, after subsequent plantings with barley, low levels of $R$. solani were detected in these cores. Some of the cores taken from patches in the Australian studies also failed to yield $R$. solani $(19,20)$. Some of the patches were sampled with five cores in each patch and, in many cases, not all cores within a patch yielded $R$. solani. In one study, 13 of 25 cores were negative (20). This could have been due to the difficulty of isolating Rhizoctonia spp. from roots.

Our results also demonstrate that $R$. oryzae probably is not involved in patch formation. The levels of this pathogen were low and not significantly different among any of the patch positions. In Australia, Waitea spp. (the perfect stage of $R$. oryzae) was found to be randomly distributed within and between patches, although there were higher levels between patches in one experiment (20). Although $R$. oryzae has not been found to be associated with patches in eastern Washington, isolates can cause severe stunting of barley, wheat, and pea $(30,32,37)$.

In summary, this technique can be used to follow the hyphal activity of $R$. solani and $R$. oryzae in field soils. This will be useful to investigate how Rhizoctonia spp. are affected by cropping practices such as

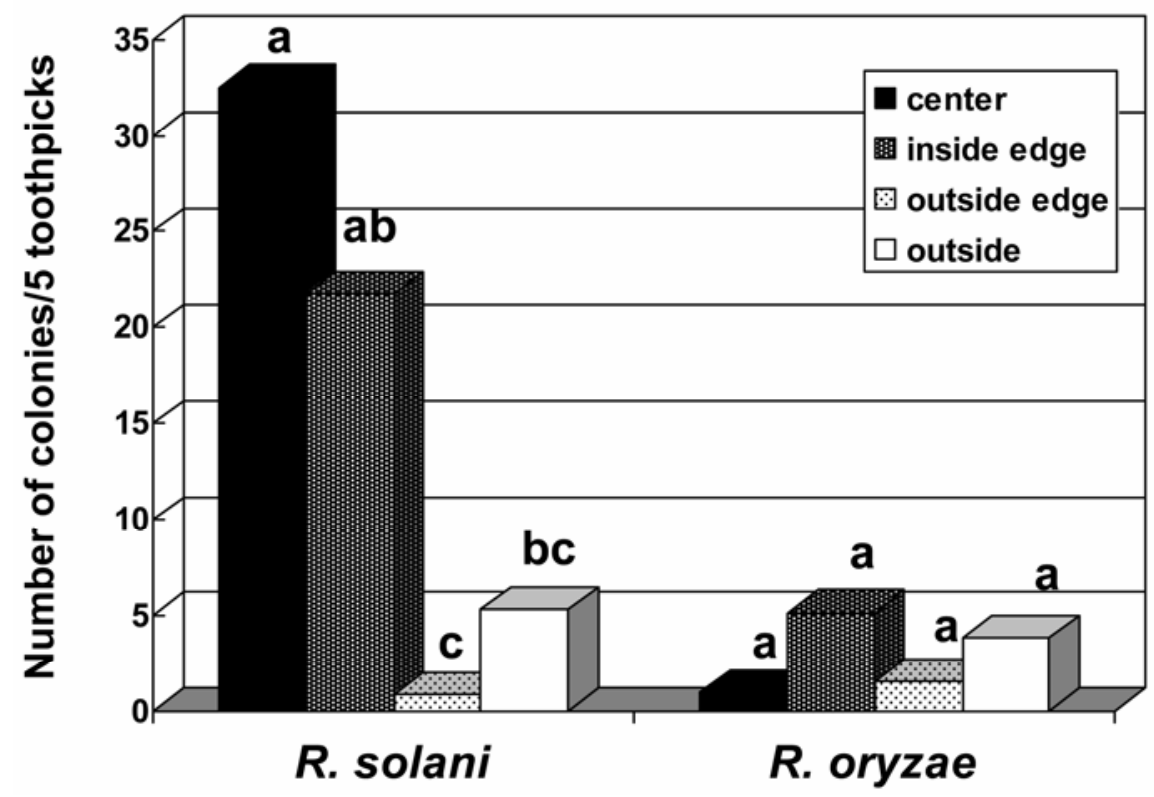

Fig. 5. Colonization of toothpicks from intact soil cores taken from four positions within and around Rhizoctonia bare patches, Jirava Farm, Ritzville, WA (Ritzville silt loam). Values are averages from eight patch transects, taken from the first planting of the cores. Center: center of patch; inside edge: 1 $\mathrm{m}$ inside the boundary of the patch; outside edge: $1 \mathrm{~m}$ outside the boundary of the batch; and outside: from healthy, not stunted plants outside of the patch. Within each species, bars with the same letters are not significantly different, using a least significant difference test $(P=0.05)$.

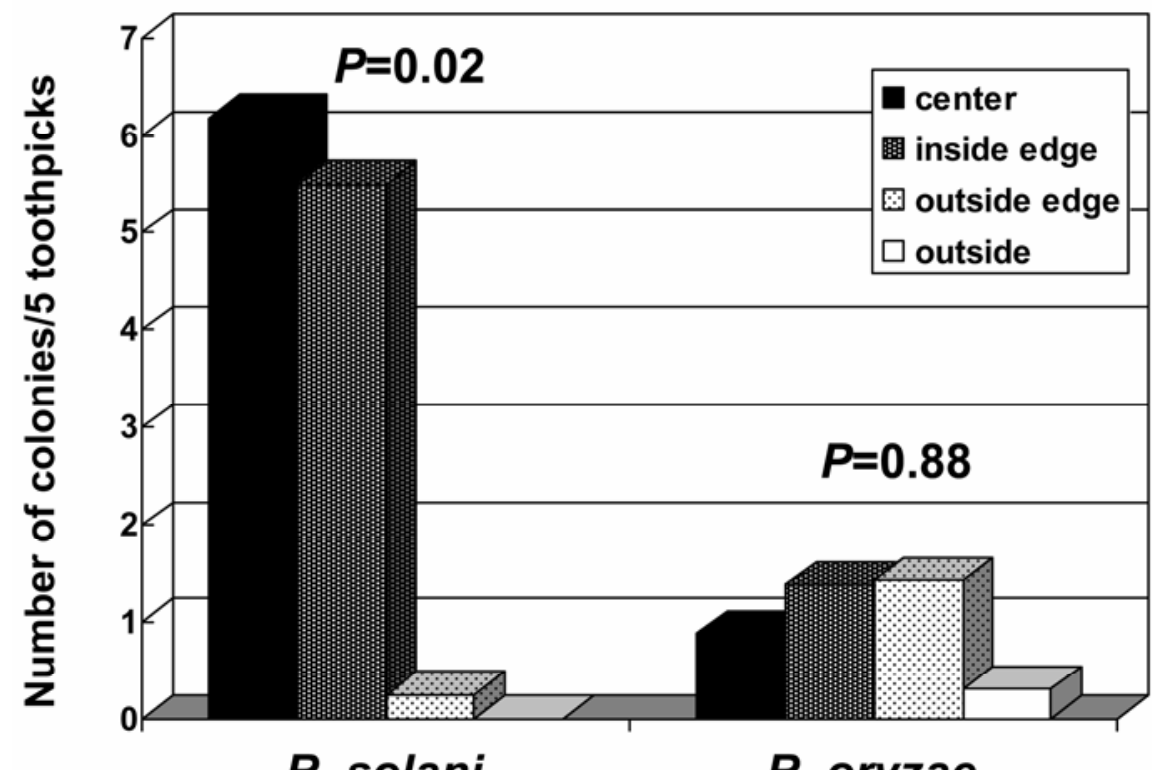

R. solani

R. oryzae

Fig. 6. Colonization of toothpicks from intact soil cores taken from four positions within and around Rhizoctonia bare patches, Mead Farm, Starbuck, WA (Walla Walla silt loam). Values are averages from eight patch transects, taken from the second planting of the cores. Center: center of patch; inside edge: $1 \mathrm{~m}$ inside the boundary of the patch; outside edge: $1 \mathrm{~m}$ outside the boundary of the batch; and outside: from healthy, not stunted plants outside of the patch. Data was analyzed with Kruskal-Wallis one-way analysis of variance. Differences among positions were significant for Rhizoctonia solani $(P=0.02)$ but not significant for $R$. oryzae $(P=0.88)$. 
tillage, crop rotation, and weed (greenbridge) management. This method also can detect the presence or absence of these pathogens from soil samples, and give growers useful information that can be used for management decisions.

\section{ACKNOWLEDGMENTS}

We thank K. Adams for her assistance in conducting these trials. We also thank farmer cooperators Ron Jirava and Skip Mead.

\section{LITERATURE CITED}

1. Armentrout, V. N., Downer, J. A., Grasmick, D. L., and Weinhold, A. R. 1987. Factors affecting infection cushion development by Rhizoctonia solani on cotton. Phytopathology 77:623-630.

2. Bailey, D. J., Otten, W., and Gilligan, C. A. 2000. Saprotrophic invasion by the soil-borne fungal plant pathogen Rhizoctonia solani and percolation thresholds. New Phytol. 146:535544.

3. Chung, Y. R., Hoitink, H. A. J., Dick, W. A., and Herr, L. J. 1988. Effects of organic matter decomposition level and cellulose amendment on the inoculum potential of Rhizoctonia solani in hardwood bark media. Phytopathology 78:836-840.

4. Clark, C. A., Sasser, J. N., and Barker, K. R. 1978. Elutriation procedures for quantitative assay of soils for Rhizoctonia solani. Phytopathology 68:1234-1236.

5. Daniels, J. 1963. Saprophytic and parasitic activities of some isolates of Corticium solani. Trans. Br. Mycol. Soc. 46:485-502.

6. Deacon, J. W. 1996. Translocation and transfer in Rhizoctonia: Mechanisms and significance. Pages 117-125 in: Rhizoctonia Species: Taxonomy, Molecular Biology, Ecology, Pathology and Disease Control. B. Sneh, S. JabajiHare, S. Neate, and G. Dijst, eds. Kluwer Academic Publishers, Dordrecht, The Netherlands.

7. Garrett, S. D. 1962. Decomposition of cellulose in soil by Rhizoctonia solani Kühn. Trans. Br. Mycol. Soc. 45:115-120.

8. Garrett, S. D. 1970. Pathogenic Root-Infecting Fungi. Cambridge University Press, Cambridge.

9. Gilligan, C. A., and Bailey, D. J. 1997. Components of pathozone behaviour. New Phytol. 115:223-242.

10. Gilligan, C. A., Simons, S. A., and Hide, G. A. 1996. Inoculum density and spatial pattern of Rhizoctonia solani in field plots of Solanum tuberosum: effects of cropping frequency. Plant Pathol. 45:232-244.

11. Harris, K., Young, I. M., Gilligan, C. A., Otten, W., and Ritz, K. 2003. Effect of bulk density on the spatial organisation of the fungus Rhizoctonia solani in soil. FEMS Microbiol. Ecol. 44:45-56.

12. Henis, Y., Ghaffar, A., Baker, R., and Gillespie, S. L. 1978. A new pellet soil-sampler and its use for the study of population dynamics of Rhizoctonia solani in soil. Phytopathology 68:371-676.

13. Ko, W-H., and Hora, F. K. 1971. A selective medium for the quantitative determination of Rhizoctonia solani in soil. Phytopathology 61:707-710.
14. Kumar S., Sivasithamparam, K., Gill, J. S., and Sweetingham, M. W. 1999. Temperature and water potential effects on growth and pathogenicity of Rhizoctonia solani AG-11 to lupin. Can. J. Microbiol. 45:389-395.

15. LaMondia, J. A. 1999. Influence of rotation crops on the strawberry pathogens Pratylenchus penetrans, Meloidogyne hapla, and Rhizoctonia fragariae. J. Nematol. 31:650655.

16. Lees, A. K., Cullen, D. W., Sullivan, L., and Nicolson, M. J. 2002. Development of conventional and quantitative real-time PCR assays for the detection and identification of Rhizoctonia solani AG-3 in potato and soil. Plant Pathol. 51:293-302.

17. MacNish, G. C. 1984. The use of undisturbed soil cores to study methods of controlling rhizoctonia patch of cereals. Plant Pathol. 33:355-359.

18. MacNish, G. C. 1985. Methods of reducing rhizoctonia patch of cereals in Western Australia. Plant Pathol.34:175-181.

19. MacNish, G. C., McLernon, C. K., and Wood, D. A. 1993. The use of zymogram and anastomosis techniques to follow the expansion and demise of two coalescing bare patches caused by Rhizoctonia solani AG-8. Aust. J. Agric. Res. 44:1161-1173.

20. MacNish, G. C., and Sweetingham, M. W. 1993. Evidence that each rhizoctonia bare patch is dominated by an individual zymogram group (ZG) of Rhizoctonia solani AG-8. Aust. J. Agric. Res. 44:1175-1194.

21. Matthew, J. S., and Brooker, J. D. 1991. The isolation and characterization of polyclonal antibodies to anastomosis group 8 of Rhizoctonia solani. Plant Pathol. 40:67-77.

22. Mazzola, M., Wong, O. T., and Cook, R. J. 1996. Virulence of Rhizoctonia oryzae and $R$. solani AG-8 on wheat and detection of $R$. oryzae in plant tissue by PCR. Phytopathology 86:354-360.

23. Murray, D. I. L. 1981. Rhizoctonia solani causing barley stunt disorder. Trans. Br. Mycol. Soc. 76:383-395

24. Nicholson, P., Turner, A. S., Edwards, S. G., Bateman, G. L. Morgan, L. W., Parry, D. W., Marshall, J., and Nuttall, M. 2002. Development of stem-base pathogens on different cultivars of winter wheat determined by quantitative PCR. Eur. J. Plant Pathol. 108:163-177.

25. Ogoshi, A., Cook, R. J., and Bassett, E. N. 1990. Rhizoctonia species and anastomosis groups causing root rot of wheat and barley in the Pacific Northwest. Phytopathology 80:784788.

26. Otten, W., and Gilligan, C. A. 1998. Effect of physical conditions on the spatial and temporal dynamics of the soil-borne fungal pathogen Rhizoctonia solani. New Phytol. 138:629-637.

27. Papavizas, G. C. 1968. Survival of rootinfecting fungi in soil. VIII. Distribution of Rhizoctonia solani in various physical fractions of naturally and artificially infested soil Phytopathology 58:746-751.

28. Papavizas, G. C. 1970. Colonization and growth of Rhizoctonia solani in soil. Pages 108-122 in: Rhizoctonia solani: Biology and Pathology. J. R. Parmeter, ed. University of California Press, Berkeley.
29. Papavizas, G. C., and Davey, C. B. 1962. Isolation and pathogenicity of Rhizoctonia saprophytically existing in soil. Phytopathology 52:834-840.

30. Paulitz, T. C. 2002. First report of Rhizoctonia oryzae on pea. Plant Dis. 86:442.

31. Paulitz, T. C., Smiley, R., and Cook, R. J. 2002. Insights into the prevalence and management of soilborne cereal pathogens under direct seeding in the Pacific Northwest, U.S.A. Can. J. Plant Pathol. 24:416-428.

32. Paulitz, T. C., Smith, J., and Kidwell, K. 2002 Virulence of Rhizoctonia oryzae on wheat and barley cultivars from the Pacific Northwest. Plant Dis. 87:51-55.

33. Paulitz, T. C., Zhang, H., and Cook, R. J. 2003. Spatial distribution of Rhizoctonia oryzae and Rhizoctonia root rot in direct-seeded cereals. Can. J. Plant Pathol. 25:295-303.

34. Pumphrey, F. V., Wilkins, D. E., Hane, D. C., and Smiley, R. W. 1987. Influence of tillage and nitrogen fertilizer on Rhizoctonia root rot (bare patch) of winter wheat. Plant Dis. 71:125-127.

35. Roget, D. K., Neate, S. M., and Rovira, A. D. 1996. Effect of sowing point design and tillage practice on the incidence of rhizoctonia root rot, take-all and cereal cyst nematode in wheat and barley. Aust. J. Exp. Agric. 36:683-693.

36. Schroeder, K. L. 2004. The dynamics of root diseases of wheat and barley in the transition from conventional tillage to direct seeding. Ph.D dissertation, Washington State University, Pullman.

37. Schroeder, K. L., and Paulitz, T. C. 2002. Development of Rhizoctonia root rot of barley in soils from conventional and no-till fields. (Abstr.) Phytopathology 92:S74

38. Smiley, R. W., Collins, H. P., and Rasmussen, P. E. 1996 Diseases of wheat in long-term agronomic experiments at Pendleton, Oregon. Plant Dis. 80:813-820.

39. Smith, J. D., Kidwell, K. K., Evans, M. A., Cook, R. J., and Smiley, R. W. 2003. Assessment of spring wheat genotypes for disease reaction to Rhizoctonia solani AG-8 in controlled environment and direct-seeded field evaluations. Crop Sci. 43:697-700.

40. Smith, J. D., Kidwell, K. K., Evans, M. A., Cook, R. J., and Smiley, R. W. 2003. Evaluation of spring cereal grains and wild Triticum germplasm for resistance to Rhizoctonia solani AG-8. Crop Sci. 43:701-709.

41. Sneh, B., Katan, J., Henis, Y., and Wahl, I. 1966. Methods for evaluating inoculum density of Rhizoctonia in naturally infected soil. Phytopathology 56:74-78.

42. Thornton, C. R., and Gilligan, C. A. 1999. Quantification of the effect of the hyperparasite Trichoderma harzianum on the saprotrophic growth dynamics of Rhizoctonia solani in compost using a monoclonal antibody-based ELISA. Mycol. Res. 103:443-448.

43. Weller, D. M., Cook, R. J., MacNish, G., Bassett, E. N., Powelson, R. L., and Petersen, R. R. 1986. Rhizoctonia root rot of small grains favored by reduced tillage in the Pacific Northwest. Plant Dis. 70:70-73.

44. Weinhold, A. R. 1977. Population of Rhizoctonia solani in agricultural soils determined by a screening procedure. Phytopathology 67:566569. 